\title{
Hypolipidemic Properties of Cocoa and Coffee By-Products after Simulated Gastrointestinal Digestion: A Comparative Approach ${ }^{\dagger}$
}

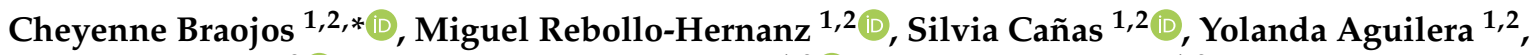 \\ Silvia M. Arribas ${ }^{3}{ }^{\circ}$, María. A. Martín-Cabrejas ${ }^{1,2}{ }^{\oplus}$ and Vanesa Benítez ${ }^{1,2, *}$ \\ 1 Department of Agricultural Chemistry and Food Science, Universidad Autónoma de Madrid, \\ 28049 Madrid, Spain; miguel.rebollo@uam.es (M.R.-H.); silvia.cannas@uam.es (S.C.); \\ yolanda.aguilera@uam.es (Y.A.); maria.martin@uam.es (M.A.M.-C.) \\ 2 Institute of Food Science Research, CIAL (UAM-CSIC), 28049 Madrid, Spain \\ 3 Department of Physiology, Universidad Autónoma de Madrid, 28029 Madrid, Spain; silvia.arribas@uam.es \\ * Correspondence: cheyenne.braojos@uam.es (C.B.); vanesa.benitez@uam.es (V.B.) \\ + Presented at the 1st International Electronic Conference on Biomedicine, 31 May-25 Jun 2021; \\ Available online: https://ecb2021.sciforum.net/.
}

Citation: Braojos, C.;

Rebollo-Hernanz, M.; Cañas, S.;

Aguilera, Y.; Arribas, S.M.;

Martín-Cabrejas, M.A.; Benítez, V. Hypolipidemic Properties of Cocoa and Coffee By-Products after Simulated Gastrointestinal Digestion: A Comparative Approach. Biol. Life Sci. Forum 2021, 7, 1. https:// doi.org/10.3390/ECB2021-10288

Academic Editor: Ciro Isidoro

Published: 1 June 2021

Publisher's Note: MDPI stays neutral with regard to jurisdictional claims in published maps and institutional affiliations.

Copyright: (C) 2021 by the authors Licensee MDPI, Basel, Switzerland. This article is an open access article distributed under the terms and conditions of the Creative Commons Attribution (CC BY) license (https:// creativecommons.org/licenses/by/ $4.0 /)$.

\begin{abstract}
New sustainable ingredients with beneficial properties for health are a main goal for the food industry. In this regard, the cocoa shell (CS) and the coffee pulp (CP), by-products from the coffee and cocoa industry produced worldwide in large amounts, are suitable candidates. We previously stated that these by-products are sources of phytochemicals and dietary fiber with potential hypolipidemic properties. This study aimed to assess the hypolipidemic properties of CS and CP after simulated gastrointestinal digestion. The capacities of the residual fraction of each digestion phase to bind bile salts and cholesterol and inhibit the lipase activity were measured to establish the in vitro hypolipidemic properties of both by-products. Furthermore, the digested fractions' effect on lipid accumulation was evaluated in the HepG2 cell line. From results, the CS showed a higher ability to bind cholesterol (4-24\%) and bile salts (2-3\%) in gastric and colonic phases. Meanwhile, during the gastrointestinal phase, CP showed a greater capacity to bind cholesterol $(1-13 \%)$ and bile salts $(2 \%)$. The capacity to inhibit lipase activity was more accentuated in the CS in gastrointestinal digestion (16\%) whereas during gastric digestion in the CP (11\%). Likewise, the digested fractions of both by-products $(100 \mu \mathrm{g} / \mathrm{mL})$ significantly alleviated the accumulation of fat (17-20\%) in the HepG2 cell model after the stimulation of cells with palmitic acid. This comparative approach suggests that both by-products exhibit similar hypolipidemic properties after in vitro digestion. This research supports the revalorization of cocoa and coffee by-products as food ingredients and nutraceuticals with potential health benefits in preventing chronic metabolic diseases. due to their remarkable hypolipidemic properties.
\end{abstract}

Keywords: cocoa shell; coffee pulp; gastrointestinal digestion; hypolipidemic properties; hypocholesterolemic; novel ingredients

\section{Introduction}

Cocoa and coffee are two of the most consumed products in the world. The annual world gross cocoa harvest for the 2019 period was 4726 thousand tons, and it is expected to increase by approximately $2.5 \%$ in 2020 [1]. Regarding coffee, world production reached 163.7 million $60 \mathrm{~kg}$ bags in the same period [2]. During cocoa bean and coffee cherry processing, approximately $90 \%$ of the products are discarded as wastes, which sometimes are not appropriately handled, causing high environmental impact [3-5]. The cocoa shell (CS) is the tegument that coats the cocoa bean and is obtained during its roasting process [5]. The cocoa shell is about $10-17 \%$ of the total weight of the cocoa bean, representing 
approximately 800 tons of waste, which revalorization leads to economic and environmental benefits [1]. The cocoa shell is a source of carbohydrates $(62 \%)$, proteins $(10-27 \%)$, dietary fiber (DF) (59\%), and valuable bioactive compounds (methylxanthines, phenolic compounds, among others) [6,7]. The coffee pulp (CP) is one of the coffee by-products obtained during the wet processing of coffee beans, and it represents $29 \%$ dry weight of the whole cherry $[8,9]$. Coffee pulp composition includes dietary fiber $(57 \%)$, carbohydrates $(20 \%)$, protein $(11 \%)$, and fat $(3 \%)$, as well as valuable bioactive compounds $[3,10]$.

Although both by-products have been used for different purposes, such as animal feed or fertilizers, a promising green application is their utilization as new sustainable food ingredients with beneficial properties for health. The CS and the $\mathrm{CP}$ have been declared safe ingredients, and their characteristics and composition make them a potential source of nutrients and beneficial compounds $[5,10]$. Previous studies have established a relationship between phytochemicals from both the CS and the $\mathrm{CP}$ and the regulation of biomarkers of metabolic syndrome $[3,7,11,12]$. Recent research proposes that the digestion process positively influences the hypolipidemic properties of both by-products $[13,14]$. Therefore, the main objective of this study was to assess the in vitro hypolipidemic properties of the CS and the CP, and its biological activity in HepG2 cells, after in vitro simulated gastrointestinal digestion.

\section{Materials and Methods}

\subsection{Reagents}

Dulbecco's Modified Eagle Medium low glucose (1000 mg/mL) (DMEM) and 0.25\% trypsin-EDTA were obtained from GE Healthcare Life Sciences. Fetal Bovine Serum (FBS), penicillin-streptomycin $(100 \times)$ were acquired from Gibco Life Technologies. oPhthalaldehyde, furfural, bile salts, lipase, Tween ${ }^{\circledR}$ 20, Bovine Serum Albumin (BSA), Palmitic Acid (PA), 2' $7^{\prime}$-Dichlorofluorescein diacetate (DCFDA), and Oil Red O were purchased from Sigma-Aldrich. 3-(4,5-dimethylthiazol-2-yl)-5-(3-carboxymethoxyphenyl)-2-(4sulfophe- nyl)-2H-tetrazolium (MTS) was purchased from Promega Corporation (Carlsbad, CA, USA). All other chemicals and reagents were obtained from Panreac (Barcelona, Spain), unless otherwise specified. The CS was kindly provided by Chocolates Santocildes (Castrocontrigo, León, Spain). The CP was kindly supplied by AORA Health (Spain).

\subsection{Cocoa Shell and Coffee Pulp Flour and Aqueous Extracts Preparation}

The by-products were processed in a mill to obtain the flours. Aqueous extracts were obtained according to the conditions described by Rebollo-Hernanz et al. [15,16].

\subsection{INFOGEST Static In Vitro Simulated Digestion}

In vitro gastrointestinal digestions were carried out following the INFOGEST method [17]. In vitro simulated colonic digestions were performed following the method previously described by Papillo et al. [18].

\subsection{Cholesterol-Binding Capacity}

To measure the binding capacity of the residual fraction from the flour digestion of both by-products, $0.1 \mathrm{~g}$ of the residual fraction from each of the sample digestion phases was incubated with $2 \mathrm{~mL}$ of egg yolk diluted 1:10 at different $\mathrm{pH}(\mathrm{pH} 2$ and $\mathrm{pH} 7$ ), and incubated with agitation $\left(2 \mathrm{~h}, 37^{\circ} \mathrm{C}, 750 \mathrm{rpm}\right)$, followed by centrifugation $(800 \times g, 15 \mathrm{~min})$. Subsequently, $0.1 \mathrm{~mL}$ of the supernatant were mixed with $0.6 \mathrm{~mL}$ of pure acetic acid, 0.2 $\mathrm{mL}$ of $\mathrm{H}_{2} \mathrm{SO}_{4}(96 \%)$, and $0.1 \mathrm{~mL}$ of o-phthalaldehyde $(0.6 \mathrm{mg} / \mathrm{mL})$ and incubated with agitation ( $30 \mathrm{~min}, 60^{\circ} \mathrm{C}, 750 \mathrm{rpm}$ ). The absorbance was read at $550 \mathrm{~nm}$ using a microplate reader (Cytation 5, Biotek) [19].

\subsection{Bile Salts-Binding Capacity}

For the measure of the residue's bile salts-binding capacity, $0.1 \mathrm{~g}$ of the residual fraction of gastric and intestinal flour digestion of both by-products were mixed with a solution of 
$\mathrm{NaCl}(15 \mathrm{M}, \mathrm{pH} 7.0)$ and sodium cholate $(4.65 \mathrm{mM})$, incubated $\left(3 \mathrm{~h}, 37^{\circ} \mathrm{C}, 750 \mathrm{rpm}\right)$, and centrifuged $(800 \times g, 15 \mathrm{~min})$. After that, an aliquot of the supernatants $(0.1 \mathrm{~mL})$ was added to $0.6 \mathrm{~mL}, \mathrm{H}_{2} \mathrm{SO}_{4}(45 \%)$, and $0.1 \mathrm{~mL}$ furfural $(0.3 \%)$ and incubated with shaking until the color development $\left(30 \mathrm{~min}, 65^{\circ} \mathrm{C}, 750 \mathrm{rpm}\right)$. The absorbance was measured by triplicate at $620 \mathrm{~nm}$ using a microplate reader [19].

\subsection{Inhibitory Activity against Pancreatic Lipase}

To evaluate the inhibition ability against pancreatic lipase, $0.1 \mathrm{~g}$ of the residual fraction of each digestion phase of both by-products were mixed with olive oil $(2 \mathrm{~mL})$, lipase $(2 \mathrm{~mL}$, $0.75 \mathrm{mg} / \mathrm{mL}$ ), bile salts $(5 \mathrm{~mL})$, and phosphate-buffered saline (PBS) $10 \mathrm{X}(5 \mathrm{~mL}, \mathrm{pH} 7.2)$. The samples were incubated $\left(37^{\circ} \mathrm{C}, 1 \mathrm{~h}\right)$, then the reaction was stopped by placing the samples on ice for $5 \mathrm{~min}$, followed by centrifugation $(800 \times g, 15 \mathrm{~min})$. Supernatants of the oil-containing samples were then emulsified by the addition of Tween ${ }^{\circledR} 20(0.2 \mathrm{~mL})$. Finally, the lipase activity of each of the samples was titrated with $\mathrm{NaOH}(0.02 \mathrm{M})$ and phenolphthalein [20].

\subsection{Sample Preparation for HepG2 Cells}

The digested fractions of the cocoa shell flour (CSF) and extract (CSE) and of the coffee pulp flour (CPF) and extract (CPE) were diluted in PBS $1 \times$ and filtered with $0.45 \mu \mathrm{m}$ cellulose acetate filters.

\subsection{HepG2 Cell Cultures}

HepG2 cells obtained from ATCC (Rockville, MD, USA) were cultured in DMEM low glucose $(1 \mathrm{~g} / \mathrm{mL}$ glucose) supplemented with $10 \%$ FBS and $1 \%$ penicillin/streptomycin at $37{ }^{\circ} \mathrm{C}$ in a humidified atmosphere containing $5 \% \mathrm{CO}_{2}$. To evaluate the cytotoxicity, HepG2 cells were seeded at $5 \times 10^{5}$ cells $/ \mathrm{mL}$ in 96-well culture plates and incubated for $24 \mathrm{~h}$. On day 2, cells were treated with CSF, CSE, CPF, and CPE (50-250 mg/mL) and left incubating at $37^{\circ} \mathrm{C}$ and $5 \% \mathrm{CO}_{2}$ for $24 \mathrm{~h}$. On day 3, cell viability assay was performed with the CellTiter $96^{\circledR}$ AQueous MTS Reagent Powder (Promega Corporation) according to the manufacturer's instructions.

\subsubsection{Non-Alcoholic Fatty Liver Disease Induction in HepG2 Cells}

HepG2 cells were seeded onto a $0.32 \mathrm{~cm}^{2}$ grown area 96 well flat bottom plate at a density of $10^{5}$ cells $/ \mathrm{cm}^{2}$ and incubated for $24 \mathrm{~h}$. On day 2, non-alcoholic fatty liver disease (NAFLD) was induced in HepG2 cells with PA $(500 \mu \mathrm{M})$, the digested fractions (CSF, CSE, $\mathrm{CPF}$, and CPE) were applied at a subtoxic concentration $(100 \mu \mathrm{g} / \mathrm{mL})$ for $24 \mathrm{~h}$ at $37^{\circ} \mathrm{C}$ and $5 \% \mathrm{CO}_{2}$. To prepare the PA solution, PA was conjugated with DMEM containing $1 \%$ BSA. Control cells were treated with $1 \%$ BSA only. NAFLD induction was determined by measuring the intracellular reactive oxygen species (ROS) formation by adding DCFDA $(25 \mu \mathrm{M})$. Fluorescence intensity was detected using a fluorescence microplate reader at an excitation/emission wavelength at $485 \mathrm{~nm} / 530 \mathrm{~nm}$, respectively. DCFDA was prepared according to the manufacturer's instructions.

\subsubsection{Biological Hypolipidemic Activity}

The accumulation of total lipids was performed as previously described by RebolloHernanz et al. [21] using Oil Red O. The intracellular triglycerides (TAG) content was measured using a TAG colorimetric assay kit (Spinreact) according to manufacturer's instructions. Fatty Acid Synthase (FASN) Activity was carried out as previosly described by Rebollo-Hernanz et al. [21].

\subsection{Statistical Analysis}

All experiments were carried out in triplicate. All values are expressed as the mean \pm standard deviation (SD) $(n=3)$. The effects of treatments were assessed by one-way ANOVA followed by post hoc Tukey test. Differences with values of $p<0.05$ were defined 
as statistically significant. All analyses were performed using SPSS 24.0 (Lead Technologies, Chicago, IL, USA).

\section{Results and Discussion}

3.1. Comparison of the In Vitro Hypolipidemic Properties of Cocoa Shell Flour and Coffee Pulp Flour Non-Digestible Fraction after In Vitro Static Digestion

Figure 1A,B shows the capacity of the digestion residual fractions of CSF and CPF to bind cholesterol at pH 2 and 7, respectively. Non-digested (ND) CSF exhibited a higher cholesterol-binding capacity at $\mathrm{pH} 2$ than ND-CFP. However, the digestion process affected flour cholesterol-binding capacity at $\mathrm{pH} 2$, and non-significant differences were observed between the capacity of both by-products after digestion. As observed in Figure 1B, at pH 7 , coffee and cacao by-products brought out a similar capacity to bind cholesterol before and after the digestion process, except for the CSF residue of the colonic digestion, which showed significantly higher cholesterol-binding capacity $(24 \% p<0.05)$ than the CPF one.
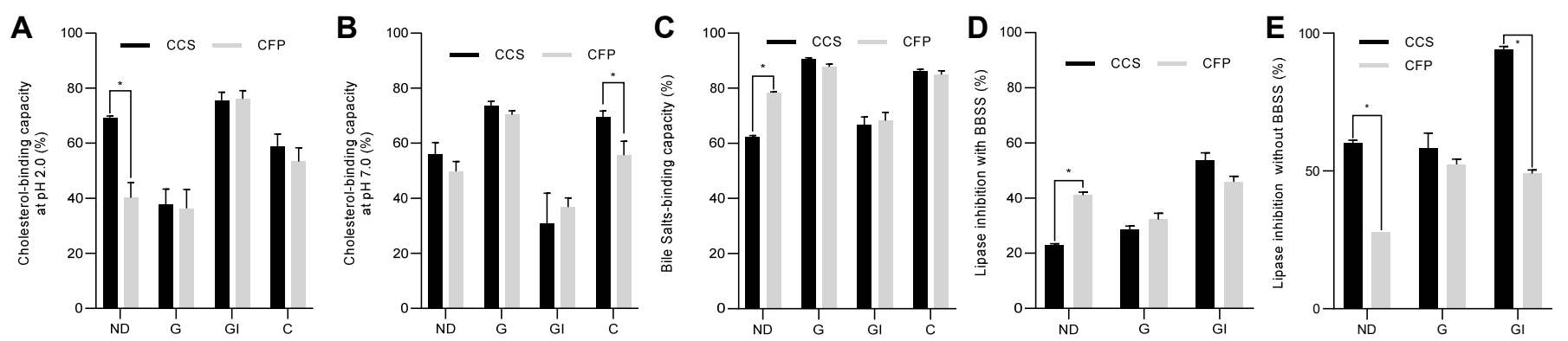

Figure 1. CSF and CPF hypolipidemic properties after the digestion process. (A) Cholesterol-binding capacity of CSF and $\mathrm{CPF}$ digested residual fractions at $\mathrm{pH}$ 2; (B) Cholesterol-binding capacity of CSF and CPF digested residual fractions at $\mathrm{pH}$ 7; (C) Bile Salts-binding capacity of CSF and CPF digested residual fractions; (D) In vitro pancreatic lipase inhibition activity of CSF and CPF with bile salts; (E) In vitro pancreatic lipase inhibition activity of CSF and CPF without bile salts. The results are expressed as mean $\pm \mathrm{SD}(\mathrm{n}=3)$. Statistically significant $(p<0.05)$ differences between paired samples according to the T-test are represented by an asterisk (*). CSF: Cocoa Shell Flour; CPF: Coffee Pulp Flour; ND: Non-digested flour; G: Gastric residual fraction; GI: Intestinal residual fraction; C: Colonic residual fraction, BBSS: Bile salts.

The digestion process modified the ability of the non-digested flours to bind bile salts, and, after digestion, there were no significant differences between the capacity of both flours to bind salts (Figure 1C). On the other hand, the differences in inhibiting lipase activity in the presence and absence of bile salts found between the undigested flours of CSF and CPF disappeared after the digestion process (Figure 1D,E). However, in the absence of bile salts, the residue of the gastrointestinal (GI) phase of CSF digestion exhibited a higher capacity to inhibit the lipase activity than GI-CPF $(102 \% p<0.05)$ (Figure 1E).

Previous studies have demonstrated the fundamental role played by the DF in the reduction of bioaccessible cholesterol during the digestion process, by direct entrapment, due to a possible change in its properties during the digestion process [22]. DF has also been shown to decrease cholesterol absorption by reducing the formation of available micelles for its absorption by reducing the surfactant activity of bile salts. Likewise, the DF and the phenolic compounds present in these by-products have been related to the inhibition of pancreatic lipase [22,23]. From results and considering the composition in DF of each by-product CS (59\%) and CP (57\%), it seems reasonable to think that their hypolipidemic properties should be similar throughout the digestion process.

\subsection{Cocoa Shell and Coffee Pulp Were Not-Toxic and Regulated PA-Stimulated ROS Production and Lipid Accumulation}

MTS Cytotoxicity assay on HepG2 proliferation was carried out with CSE, CSF, CPE, and CPF digested fractions (50-250 $\mu \mathrm{g} / \mathrm{mL}$ ). The results showed that all the concentrations used were safe and non-cytotoxic. HepG2 cells were incubated for $24 \mathrm{~h}$ with PA (500 $\mu \mathrm{M})$ 
to mimic NAFLD conditions. The PA stimulation significantly increased ROS production $(p<0.05)$ and triggered morphological changes in HepG2 cells, such as the appearance of lipid droplets inside the cells, which were significantly counteracted by the treatment with CSE, CSF, CPE, and CPF digested fractions $(100 \mu \mathrm{g} / \mathrm{mL})(p<0.05)$ (Figure 2). Furthermore, digested fractions significantly decreased $(p<0.05)$ TAG levels $(5-38 \%)$ and FASN activity $(9-41 \%)$. Therefore, results suggest that both by-products can reverse the accumulation of lipid droplets and TAG inside the cells, and could modulate hepatic lipid metabolism via inhibition of de novo lipogenesis. De novo lipogenesis is elevated during NAFLD, and represents an important source of hepatic and circulating lipids, therefore, a decrease in this activity could lead to a decrease in their levels [24,25].Previous studies have shown that CPE and CSE could have antioxidant effects on HepG2 cell lines, probably due to their phytochemical content. Furthermore, these CSE components have been shown to protect mitochondrial function, closely related to markers associated with metabolic syndrome [11,12,26,27]. Both by-products may be recommended as therapeutic or preventive NAFLD treatments.
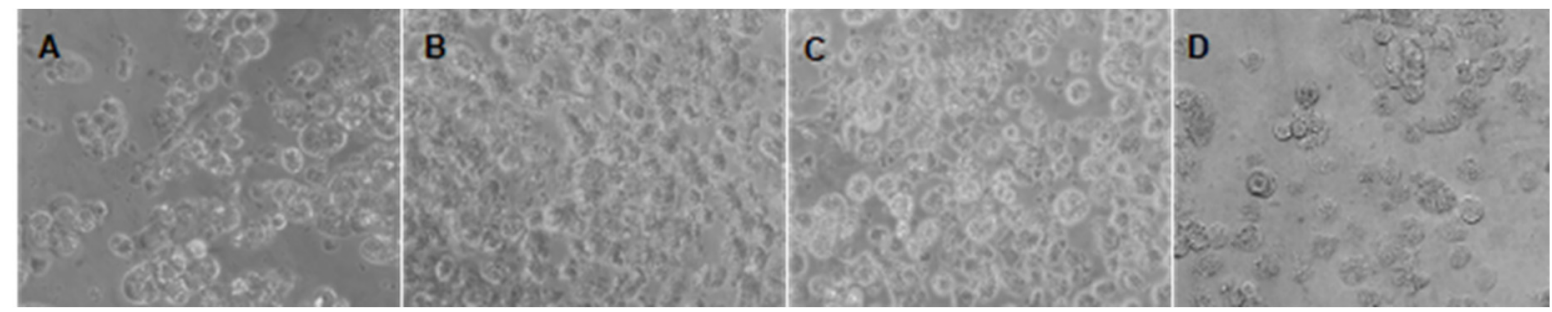

Figure 2. Illustrative representation of HepG2 morphologies after incubation in different conditions (A) Cells cultured in DMEM-BSA 1\%; (B) cells cultured in DMEM-BSA 1\% with PA (500 $\mu \mathrm{M})$; (C) cells cultured in DMEM-BSA $1 \%$ with PA (500 $\mu \mathrm{M}$ ) with treatment (Intestinal CPE, $100 \mu \mathrm{g} / \mathrm{mL})$; (D) cells cultured in DMEM-BSA 1\% with PA $(500 \mu \mathrm{M})$ with treatment (Gastric CSE, $100 \mu \mathrm{g} / \mathrm{mL}$ ).

\section{Conclusions}

This study indicates the CS and the CP exhibit similar valuable hypolipidemic properties after in vitro digestion and supports the revalorization of both by-products as novel healthy food ingredients with potential beneficial properties to prevent chronic metabolic diseases. Further investigations need to be completed to confirm their hypolipidemic properties in vivo.

Author Contributions: Conceptualization, M.R.-H., V.B., Y.A., and M.A.M.-C.; formal analysis, C.B. and M.R.-H.; investigation, C.B.; data curation, C.B., S.C., M.A.M.-C. and V.B.; writing-original draft preparation, C.B., M.R.-H., M.A.M.-C. and V.B.; writing-review and editing, C.B., M.R.-H., M.A.M.-C. and V.B.; supervision, V.B. and M.A.M.-C.; funding acquisition S.M.A. and M.A.M.-C. All authors have read and agreed to the published version of the manuscript.

Funding: This research was funded by the COCARDIOLAC project from the Spanish Ministry of Science and Innovation (RTI 2018-097504-B-I00). C. B. received funding from the Youth Guarantee Grant of the Community of Madrid for her predoctoral fellowship (PEJD-2019-PRE/BIO-16499). M.R.H. received funding from the FPU program of the Ministry of Universities for his predoctoral fellowship (FPU15/04238). Aid is funded through the Excellence Line for University Teaching Staff within the Multiannual Agreement between the Community of Madrid and the UAM (2019-2023).

Institutional Review Board Statement: Not applicable.

Informed Consent Statement: Not applicable.

Data Availability Statement: The data presented in this study are available from the corresponding author on reasonable request.

Conflicts of Interest: The authors declare no conflict of interest. 


\section{References}

1. International Cocoa Organization Production of Cocoa Beans-ICCO Quarterly Bulletin of Cocoa Statics, Vol. XLVII (2020/21). Available online: https://www.icco.org/wp-content/uploads/Production_QBCS-XLVII-No.-1.pdf (accessed on 29 April 2021).

2. International Coffee Organization World Coffee Production. 2021. Available online: https://www.ico.org/ (accessed on 29 April 2021).

3. Iriondo-DeHond, A.; Aparicio García, N.; Fernandez-Gomez, B.; Guisantes-Batan, E.; Velázquez Escobar, F.; Blanch, G.P.; San Andres, M.I.; Sanchez-Fortun, S.; del Castillo, M.D. Validation of coffee by-products as novel food ingredients. Innov. Food Sci. Emerg. Technol. 2019, 51, 194-204. [CrossRef]

4. Esquivel, P.; Jiménez, V.M. Functional properties of coffee and coffee by-products. Food Res. Int. 2012, 46, 488-495. [CrossRef]

5. Rojo-Poveda, O.; Barbosa-Pereira, L.; Zeppa, G.; Stévigny, C. Cocoa bean shell—A by-product with nutritional properties and biofunctional potential. Nutrients 2020, 12, 1123. [CrossRef]

6. Panak Balentić, J.; Ačkar, Đ.; Jokić, S.; Jozinović, A.; Babić, J.; Miličević, B.; Šubarić, D.; Pavlović, N. Cocoa Shell: A By-Product with Great Potential for Wide Application. Molecules 2018, 23, 1404. [CrossRef]

7. Rebollo-Hernanz, M.; Cañas, S.; Aguilera, Y.; Benitez, V.; Gila-Díaz, A.; Rodriguez-Rodriguez, P.; Cobeta, I.M.; de Pablo, A.L.L.; Gonzalez, M.C.; Arribas, S.M.; et al. Validation of Cocoa Shell as a Novel Antioxidant Dietary Fiber Food Ingredient: Nutritional Value, Functional Properties, and Safety. Curr. Dev. Nutr. 2020, 4, 773. [CrossRef]

8. Mussatto, S.I.; Machado, E.M.S.; Martins, S.; Teixeira, J.A. Production, Composition, and Application of Coffee and Its Industrial Residues. Food Bioprocess Technol. 2011, 4, 661-672. [CrossRef]

9. Ulloa Rojas, J.B.; Verreth, J.A.J.; Amato, S.; Huisman, E.A. Biological treatments affect the chemical composition of coffee pulp. Bioresour. Technol. 2003, 89, 267-274. [CrossRef]

10. Moreno, J.; Cozzano, S.; Mercedes Pérez, A.; Arcia, P.; Curutchet, A. Coffee Pulp Waste as a Functional Ingredient: Effect on Salty Cookies Quality. J. Food Nutr. Res. 2019, 7, 632-638. [CrossRef]

11. Rebollo-Hernanz, M.; Zhang, Q.; Aguilera, Y.; Martín-Cabrejas, M.A.; de Mejia, E.G. Cocoa Shell Aqueous Phenolic Extract Preserves Mitochondrial Function and Insulin Sensitivity by Attenuating Inflammation between Macrophages and Adipocytes In Vitro. Mol. Nutr. Food Res. 2019, 63, 1801413. [CrossRef]

12. Rebollo-Hernanz, M.; Willis, L.; Aguilera, Y.; Martin-Cabrejas, M.A.; Gonzalez de Mejia, E. Fibroblast Growth Factor 21 Signaling Activation by Selected Bioactive Compounds from Cocoa Shell Modulated Metabolism and Mitochondrial Function in Hepatocytes. Curr. Dev. Nutr. 2020, 4, 459. [CrossRef]

13. Braojos, C.; Rebollo-Hernanz, M.; Benitez, V.; Cañas, S.; Aguilera, Y.; Arribas, S.; Martin-Cabrejas, M. Simulated gastrointestinal digestion influences the in vitro hypolipidemic properties of coffee pulp, a potential ingredient for the prevention of non-alcoholic fatty liver disease. Proceedings 2020, 61, 19. [CrossRef]

14. Braojos, C.; Benitez, V.; Rebollo-Hernanz, M.; Cañas, S.; Aguilera, Y.; Arribas, S.M.; Martin-Cabrejas, M.A. Evaluation of the Hypolipidemic Properties of Cocoa Shell after Simulated Digestion Using In Vitro Techniques and a Cell Culture Model of Non-Alcoholic Fatty Liver Disease. Proceedings 2020, 70, 58. [CrossRef]

15. Rebollo-Hernanz, M.; Cañas, S.; Taladrid, D.; Bartolomé, B.; Aguilera, Y.; Martin-Cabrejas, M.A. Extraction of phenolic compounds from cocoa shell: Modeling using response surface methodology and artificial neural networks. Sep. Purif. Technol. 2021, 270, 118779. [CrossRef]

16. Rebollo-Hernanz, M.; Cañas, S.; Taladrid, D.; Benítez, V.; Bartolomé, B.; Aguilera, Y.; Martín-Cabrejas, M.A.; Rebollo-Hernanz, M.; Cañas, S.; Taladrid, D.; et al. Revalorization of coffee husk: Modeling and optimizing the green-sustainable extraction of phenolic compounds. Foods 2021, 10, 653. [CrossRef] [PubMed]

17. Brodkorb, A.; Egger, L.; Alminger, M.; Alvito, P.; Assunção, R.; Ballance, S.; Bohn, T.; Bourlieu-Lacanal, C.; Boutrou, R.; Carrière, F.; et al. INFOGEST static in vitro simulation of gastrointestinal food digestion. Nat. Protoc. 2019, 14, 991-1014. [CrossRef] [PubMed]

18. Papillo, V.A.; Vitaglione, P.; Graziani, G.; Gokmen, V.; Fogliano, V. Release of antioxidant capacity from five plant foods during a multistep enzymatic digestion protocol. J. Agric. Food Chem. 2014, 62, 4119-4126. [CrossRef]

19. Benitez, V.; Rebollo-Hernanz, M.; Hernanz, S.; Chantres, S.; Aguilera, Y.; Martin-Cabrejas, M.A. Coffee parchment as a new dietary fiber ingredient: Functional and physiological characterization. Food Res. Int. 2019, 122, 105-113. [CrossRef]

20. Benítez, V.; Rebollo-Hernanz, M.; Aguilera, Y.; Bejerano, S.; Cañas, S.; Martín-Cabrejas, M.A. Extruded coffee parchment shows enhanced antioxidant, hypoglycaemic, and hypolipidemic properties by releasing phenolic compounds from the fibre matrix. Food Funct. 2021, 12, 1097. [CrossRef]

21. Rebollo-Hernanz, M.; Zhang, Q.; Aguilera, Y.; Martín-Cabrejas, M.A.; Gonzalez de Mejia, E. Phenolic compounds from coffee by-products modulate adipogenesis-related inflammation, mitochondrial dysfunction, and insulin resistance in adipocytes, via insulin/PI3K/AKT signaling pathways. Food Chem. Toxicol. 2019, 132, 110672. [CrossRef]

22. Capuano, E. The behavior of dietary fiber in the gastrointestinal tract determines its physiological effect. Crit. Rev. Food Sci. Nutr. 2017, 57, 3543-3564. [CrossRef]

23. Story, J.A.; Kritchevsky, D. Comparison of the Binding of Various Bile Acids and Bile Salts in Vitro by Several Types of Fiber. J. Nutr. 1976, 9, 1292-1294. [CrossRef]

24. Donnelly, K.L.; Smith, C.I.; Schwarzenberg, S.J.; Jessurun, J.; Boldt, M.D.; Parks, E.J. Sources of fatty acids stored in liver and secreted via lipoproteins in patients with nonalcoholic fatty liver disease. J. Clin. Investig. 2005, 115, 1343-1351. [CrossRef] 
25. Beysen, C.; Schroeder, P.; Wu, E.; Brevard, J.; Ribadeneira, M.; Lu, W.; Dole, K.; O’Reilly, T.; Morrow, L.; Hompesch, M.; et al. Inhibition of fatty acid synthase with FT-4101 safely reduces hepatic de novo lipogenesis and steatosis in obese subjects with non-alcoholic fatty liver disease: Results from two early-phase randomized trials. Diabetes Obes. Metab. 2021, 23, 700-710. [CrossRef]

26. Baeza, G.; Amigo-Benavent, M.; Sarriá, B.; Goya, L.; Mateos, R.; Bravo, L. Green coffee hydroxycinnamic acids but not caffeine protect human HepG2 cells against oxidative stress. Food Res. Int. 2014, 62, 1038-1046. [CrossRef]

27. Rebollo-Hernanz, M.; Zhang, Q.; Aguilera, Y.; Martín-Cabrejas, M.A.; Gonzalez de Mejia, E. Relationship of the phytochemicals from coffee and cocoa by-products with their potential to modulate biomarkers of metabolic syndrome in vitro. Antioxidants 2019, 8, 279. [CrossRef] 